\title{
The principle techniques of current harmonics reduction and power factor improvement for power plants and the utilities: A review
}

\author{
${ }^{1}$ Deepak Sharma, ${ }^{2}$ Devendra Kumar Khichi, ${ }^{3}$ Vinod Kumar Sharma \\ ${ }^{1,2,3}$ Dept. Of Electrical Engg. Arya College of Engg. And Research Centre
}

\begin{abstract}
The applications of nonlinear loads are increasing worldwide, most of them are consisting power electronics devices. These nonlinear loads have made the power quality problems, a big challenge than ever before. An effective control of power quality parameters is highly dependent on their accurate and timely monitored system. Harmonics affects accurate estimation and effective control of power quality problems. In this paper, several methods of power system harmonics elimination are critically reviewed and classified based on the type of analysis tool and applications. Various estimation techniques are discussed in brief; comparison of available approaches are deeply examined and presented with the simulation models. The major issues and challenges in harmonics elimination are highlighted. The need to improve power quality in AC-to-DC converters has become the most important issue at present. Passive filters are not a solution to this as the harmonics are very high. So power electronics equipment has been used. A number of control strategies based on PWM method have emerged which cause a reduction in the harmonics and also achieves sinusoidal input current, unity power factor and high dynamic response.

Some of the most important PWM control schemes include hysteresis current control (HCC)[1.3], Sinusoidal pulse width modulation (SPWM)[1.2], indirect current control (IDC)[2], space vector modulation (SVM)[3]. The principle of operation and implementation of each scheme is discussed in detail and the advantages and disadvantages of each scheme are stated. A closed loop control system has been designed for each control strategy and the converters are simulated using the MATLAB/SIMULINK program. The performance of the converter under each control strategy is evaluated.

The next phase is to calculate various parameters of the converter like DC output voltage, THD of output voltage, THD of input current, Input current distortion factor, input power factor, input displacement factor, input harmonic factor, voltage ripple factor have been calculated. All the strategies are then compared on the basis of these parameters and graphs have been plotted to make a comparative analysis of the schemes studied.
\end{abstract}

\section{Introduction}

The applications of power electronics based non-linear loads have raised distortion of supply waveforms. These Distorted waveforms can be represented as summation of various higher frequency sinusoidal components known as harmonics. These harmonics are integer multiple of fundamental frequency. For some cases it can be certain frequency components that are not integer multiple of fundamental component, which can be termed as inter-harmonics. When this inter-harmonic frequency is less than fundamental frequency, it is known as sub harmonic. The operational efficiency and reliability of power system, loads and protective relaying is highly affected by these harmonics and inter-harmonics [1-4]. Apart from this, skin effect, eddy current loss and corona loss are the direct function of frequency and increase considerably in the presence of harmonics. Resonance phenomenon increases the losses in the system. It sometimes leads to failure of devices like compensating capacitors. Harmonic voltage drop across the system impedances results in voltage disturbances causing other linear load to draw harmonic current. It affects the protective relaying characteristics or zero crossing detection, leading to reduced selectivity and reliability of protection system. It causes interference in communication channels which is another serious ill effect of harmonics..IEEE standard 5191992 and IEC 61000 series of standards have come into effect for the Harmonics problem, because it demands serious concern for accurate estimation and reliable mitigation .Here the harmonics estimation, means, detection of frequency components present in the signal and measurement/estimation of amplitudes and phases of those frequencies. This paper presents a review of harmonic estimation techniques in the power system. The basic introduction of some useful techniques used for harmonics and inter-harmonics estimation are also discussed in brief. Comparisons of various approaches, computational burden, simulations are presented and the key issues and challenges in the harmonics estimation are highlighted. The amount of distortion in the voltage or current waveform is quantified by means of an index called the total harmonic distortion (THD). The THD in current is defined as 


$$
\mathrm{THD}=\sqrt{\sum_{\mathrm{sh}=2}^{\infty} \frac{\mathrm{Ish}^{2}}{\mathrm{Ish} 1}} \times 100 \%
$$

\section{Control Strategies}

The control signals for the single device in three phase boost rectifier are generated by comparing a control voltage with a saw tooth waveform of fixed frequency i.e. the device is switched at constant frequency. The control voltage can be obtained by comparing the output voltage with its desired value. The control and power circuit of the three phase boost rectifier are as shown in the figure 1.1:

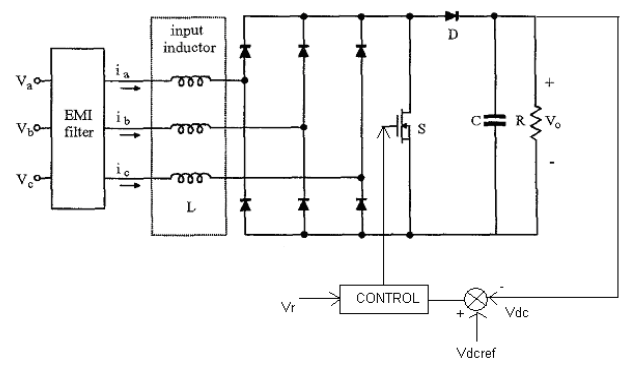

Fig 1.1 Control Circuit of a three phase boost rectifier

\subsection{Six Switch Rectifiers}

The six switch rectifiers can be controlled by any of the methods listed earlier. However the phase and amplitude control strategy is a non PWM method and is the oldest control scheme.

\section{Amplitude And Phase Control}

The circuit of a six pulse bridge converter is as shown in the figure 1.2. It consists of six thyristors. The thyristors $\mathrm{T} 1, \mathrm{~T} 3, \mathrm{~T} 5$ are called the positive group since they are turned on when the supply voltages are positive. Similarly the thyristors T4, T6, T2 which conduct when the supply voltages are negative form the negative group. . The firing angle for positive group of thyristors (T1, T3, T5) is measured from $30^{\circ}$ with reference to the positive half cycle of the phase voltage. The negative group of thyristors are turned on $180^{\circ}$ after the positive group thyristors. In each input cycle there are six pulses in the output voltage. The thyristors conduct for a period of $120^{\circ}$ each and each phase conducts the positive current for $120^{\circ}$ and negative current for $120^{\circ}$. The output voltage is obtained by conduction of two phases at any time. Because of the higher pulse number, the distortion factor of the supply current improves significantly and the output voltage ripple is considerably reduced.

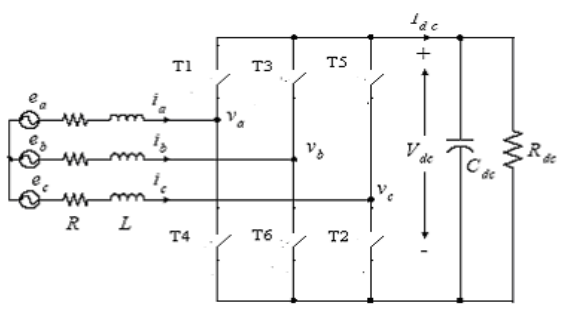

Fig 1.2 Six Pulse Bridge Converter

The six thyristors need to be triggered in a sequence so as to make the supply currents balanced. If the output current is assumed to be constant, the output voltage at any instant is equal to one of the six line voltages. This requires that two thyristors two in the positive group and one in the negative group be gated together simultaneously. In order to vary the average value of output voltage, the gate pulses to the thyristor pairs are to be controlled. The earliest instant at which each thyristor can be turned on is taken as the datum for measuring the firing angle of each thyristor i.e. the instants at which the phase voltages crossover are the reference points for the measurement of firing angles. Thus by proper generation of the firing pulses for the six thyristors the output voltage of the converter can be controlled. 


\subsection{Sinusoidal Pulse Width Modulation With Instantaneous Current Control}

The sinusoidal PWM technique is very popular for industrial converters. . In this, isosceles triangle carrier wave of frequency fc is compared with the fundamental frequency $f$ sinusoidal modulating wave, and the points of intersection determine the switching points of power devices.

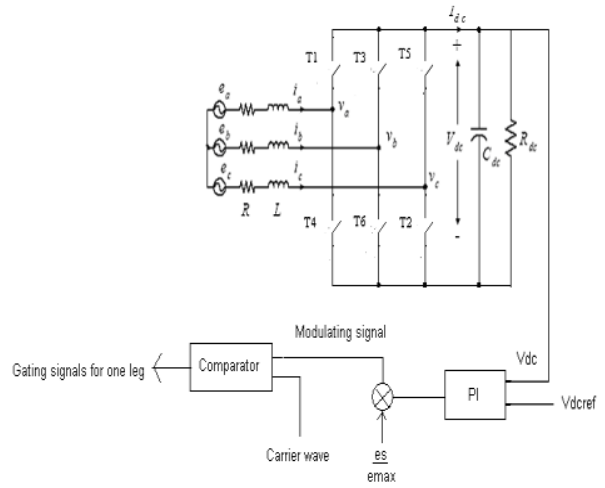

Fig 1.3 SPWM Controlled converter

The notch and pulse widths vary in sinusoidal manner so that average or fundamental component frequency is same as $f$ and its amplitude is proportional to the command modulating voltage. The same carrier wave can be used for all 3 phases. Fig 1.3 illustrates the SPWM method based on using the intersection points of the modulation signal and the triangle carrier signal as the time instants for turning the switches in a given phase, complementarily ON and OFF This method of encoding the modulating signal through the pulse width is accurate when the frequency of the carrier is sufficiently high. The modulation signal is amplified with a constant gain, without delay.

\section{Modulation Index (M.I):}

$$
M . I=\frac{\text { Amplitude_of_mod ulating _ wave }}{\text { Amplitude_of_carrier_wave }}
$$

M.I. determines the fundamental component output voltage

$>$ If $0<$ M.I $<1, \mathrm{~V}_{1}=$ M.I $\left(\mathrm{V}_{\text {in }}\right)$ where $\mathrm{V}_{1}, \mathrm{~V}_{\text {in }}$ are the fundamental of the output voltage and input DC voltage respectively

Modulation Ratio (Freq Ratio), $\mathbf{M}_{\mathbf{R} \text { : }}$

$$
M_{R}=\frac{\text { Frequency_of_carrier_wave }}{\text { Frequency_of_mod ulating_wave }}
$$

$>$ Modulation ratio determines the incident of harmonics in the spectra

$>\mathrm{f}=\mathrm{K} \cdot \mathrm{M}_{\mathrm{R}}\left(\mathrm{f}_{\mathrm{m}}\right)$, where $\mathrm{f}_{\mathrm{m}}$ is the frequency of modulating signal and $\mathrm{k}$ is integer $(1,2,3 \ldots)$

The selection of a carrier frequency depends on the trade-off between converter loss and the system loss. Higher carrier frequency increases converter switching loss but decreases the system harmonic loss. An optimal carrier frequency should be selected such that the total system loss is minimal. An important effect of PWM switching frequency is the generation of acoustic noise (known as magnetic noise) by the magnet ostriction effect when the converter supplies power to a machine. The effect can be alleviated by randomly varying the switching frequency, or it can be completely eliminated by increasing the switching frequency above the audio range. Modern high-speed IGBT's easily permit such acoustically noise-free variablefrequency drives. Low-pass line filters can also eliminate this problem.

If SPWM is applied in open loop, the results are not satisfactory. In order to control the input current, a feedback current loop is applied. In such cases the converter operates as a programmable current source. Fig 1.4 shows an instantaneous current control scheme with sinusoidal voltage PWM in the inner loop. 


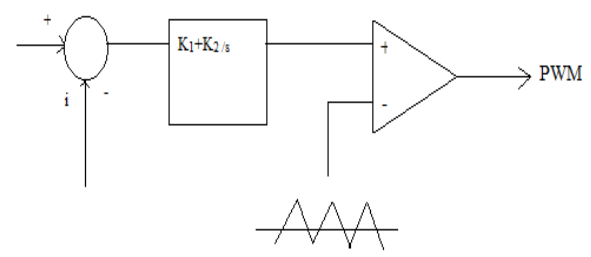

Fig 1.4 Control block diagram for instantaneous control SPWM

The error in the sinusoidal current loop is converted to sinusoidal voltage command through a proportional-integral (P-I) controller. This voltage is the compared with the carrier wave to generate the gating pulses. For a three phase converter, three similar controllers are used. The control is simple but there are a few problems. Due to limited band-width of the control system, the actual current will have a phase lag and magnitude error which will increase with frequency. Such phase deviation is very harmful in high-performance drive systems. The sinusoidal voltage command generated by the current control loop may contain ripple, which may create a multiple zero crossing problem in the SPWM comparator.

\subsection{Hysteresis Current Control}

Hysteresis-band PWM is basically an instantaneous feedback current control method of PWM where the actual current continually tracks the command current within a hysteresis band. This is a simple current control method where hysteresis comparators are used to impose a dead band or hysteresis around the reference current. This control scheme provides excellent dynamic performance because it acts quickly. Also, an inherent peak current limiting capability is provided. This technique does not need any information on system parameters.

Devices which convert between three-phase AC power and DC power are commonly called AC/DC power convertors and they can be found throughout industry in applications such as variable speed motor drives, battery chargers, arc welding equipment and uninterruptible power supplies. Often the term rectifier is used for an AC/DC power convertor whose predominant or only direction of power transfer is from AC to DC.

Similarly, the term inverter is often used when the predominant direction is from DC to AC. Many of the advances made in AC/DC power conversion can be seen to be due to research done in the area of motor speed control. Most of the early research on variable speed motor drives focused on the DC machine because of its adaptability to adjustable speed operation; consequently during that time the emphasis in AC/DC power convertor development was on rectifiers. The earliest widely used rectifier can be found in the Ward Leonard DC motor speed control sets in the form of an AC motor physically connected via the shaft to a DC generator. The variable DC output of the generator, achieved by varying the field current, is applied to the DC motor to obtain an adjustable speed machine. The advent of the semiconductor thyristor-based PCB rectifier provided a less expensive, smaller, quieter and more robust means of AC rectification than the Ward Leonard method.

Current control has gained prominence in AC-DC voltage source inverters (VSI) in recent times due to the increasing need to improve the power factor on the ac side. PWM converters are used for bidirectional power flow onto power utility grids. The current is controlled to follow a desired (generally sinusoidal) wave shape, providing control over the converter power factor. The current wave shape is used to satisfy harmonic current (THD) requirements, while the amplitude and phase are used to meet power flow requirements. Fig. 2.1 gives a general overview of a PWM converter with an inner current control loop. An optimum current control method for ac-dc power conversion is one which can accurately recreate the current reference waveform, without causing the generation of additional harmonics. A control technique which forces zero average current error (ZACE) in each switching period would satisfy this requirement. The control input is a current error signal with positive and negative going excursions of the signal, as shown in Fig. 2.2. A ZACE method will force the area of any one excursion to match the area of the previous excursion $(A+)$, in the opposite direction. This will result in an average current error of zero for the period of the two excursions, which is one switching period. Given a harmonic free sinusoidal reference signal, a ZACE controlled converter would deliver current exactly matching the reference at all frequencies up to the switching frequency. A second requirement of optimum current control in PWM ac-dc power conversion is that it be essentially a deadbeat control. In this application, this means that it must achieve ZACE operation (within the constraints of the power circuit) within one switching period from a "blind" start, where the recent history of the current error signal is unknown or is erroneous. In PWM converters with a standing phase system (described later), a standing phase transition must occur at least three times per line cycle, and preferably six times for optimum performance. Each standing phase transition is a disturbance to the current control system, which must be overcome within a switching period to eliminate any contribution to low order harmonics. 
A third requirement is that the switching frequency of the converter be maintained constant throughout the ac line cycle. Any filtering performed on the ac side of a PWM converter will attract harmonic currents from the line if there are harmonic voltages present. Hence it is desirable to minimize the filtration required from the PWM converter. Also, switching frequency effects on the drive electronics must be minimized. These objectives are more effectively met by imposing a fixed switching frequency. Finally, an optimum current control method for ac-dc power conversion should be capable of achieving the above requirements using only the current error signal in the current control function. While this is not an absolute requirement, it is desirable in a simple, robust method.

Ac-dc PWM converter current control techniques have been borrowed from "current-mode control" methods in dc-dc converters. There are numerous such methods, many of which have been applied to ac-dc power converters, including fixed and variable hysteresis control peak current controllers, dual current-mode (DCM), current error triangulation, and average current control. The above-mentioned current control methods are successful in providing reasonably accurate trans conductance (reference voltage to actual current) linearity in dc-dc power conversion, and lend that attribute to ac-dc conversion as well. However, all but the hysteresis methods allow an error between the current reference signal and the average of the actual current within a switching period, and hence do not meet the ZACE requirement. While this is acceptable in dc-dc converters where an offset between the reference and actual current is inconsequential, it is undesirable in unity power factor ac-dc converters.

The widely varying duty-cycle results in a varying offset between the current reference and the actual line current. This manifests itself as low order current harmonics, partially defeating the purpose of current control in ac-dc power conversion of the DCM method applied to a PWM converter. Basic hysteresis current control is a deadbeat ZACE method where the power circuit is switched whenever a certain hysteresis value of current error has been reached. Hysteresis current control produces no low order current harmonics. However, the switching frequency varies greatly with the duty cycle (and hence with the ac line cycle), power circuit voltages and the power circuit inductance.

Phase-locked loop (PLL) hysteresis current control offers an improvement over the basic hysteresis. Under PLL control, the hysteresis band is varied using a phase-locked-loop so as to maintain a fixed switching frequency. The disadvantage of this method is that the gain of the phase-locked loop must be sufficiently low to avoid a large switching frequency disturbance during the standing phase transition, which occurs six times per ac line cycle. In this case the standing phase transition was forced to occur at the zero crossing of the third phase voltage, although it is significantly narrower than for fixed band hysteresis.

The conventional solution to AC-DC rectification uses a diode or thyristor bridge rectifier followed by a bulk capacitor. Diode bridge rectifiers are inexpensive, highly reliable and in widespread use. Their shortcomings are: non sinusoidal line current with large harmonic content, low power factor and unregulated DC bus voltage. A large harmonic current may result in electromagnetic interference, voltage distortion and distribution losses in the electric power grid. A passive filter is often used to filter the low order harmonics, as it has a simple circuit configuration. The main drawbacks of passive filters are: bulk passive elements, fixed compensation characteristics, and series and parallel resonance with the system impedance. Active techniques to shape the line current to be a sinusoidal wave have been proposed. The reactive components and transformers of these converters are smaller than those of passive filters. Among the high power factor converters, the boost type is the most popular for drawing a sinusoidal current from the $\mathbf{A C}$ mains with nearly unity power factor. The DC side voltage of the boost converter is always higher than the peak voltage of the AC mains. The buck type AC-DC converters provide a DC bus voltage smaller than the peak voltage of the AC mains. The buck converters can limit the input inrush current and DC short-circuits current. However, the high voltage stresses of the power devices are the main drawbacks if the circuits are used in medium voltage or high power applications. To reduce the voltage stresses of power devices, series connection of power semiconductors such as IGBT and IGCT is considered. The multilevel PWM scheme is an alternative for improving the quality of the voltage waveform and reducing the electromagnetic interference generated by the converter or inverter. The multilevel converters can extend the rated converter power and voltage by increasing the number of AC side voltage levels. Without the increase in actual switching frequency, the equivalent switching frequency of the multilevel converter can be increased. This results in reduced ripple voltage on the AC side of the converter and electromagnetic interference. However, the complex control scheme and the required increase in power switches [13] are the main disadvantages if the AC-DC converter only operates in the rectification mode.

A new single-phase three-level PWM rectifier with a simple control scheme to achieve a high input power factor and low current harmonic distortion is proposed. To generate a three-level voltage pattern on the $\mathrm{AC}$ side of the proposed rectifier, a region detector for line voltage, a capacitor voltage compensator and a current controller are employed in the proposed control algorithm. Based on the proposed control strategy, the power switches are turned on or off to draw a nearly sinusoidal line current in phase with the mains voltage. The voltage stress on the power switches is clamped to half of the DC-link voltage. The proposed rectifier can 
be used in the front stage of the online uninterruptible power supply, AC/AC converter or high power switching mode power supply.

However, unlike the Ward Leonard method, the phase-controlled rectifier does not have sinusoidal line currents, and the power factor becomes progressively poorer as the DC output voltage decreases. Furthermore, although the device is capable of bidirectional power transfer, a second device is required if motor reversing is desired. Still, the advantages of the haze controlled rectifier are seen to far outweigh its disadvantages, and the use of Ward Leonard sets has rapidly declined since. During the past 15 years a considerable amount of research has been done in the area of AC motor speed control. Most modern variable speed drives incorporate a two stage convertor configuration, in which the utility supply is first rectified to form a constant voltage or current DC link, from which an inverter derives a variable frequency and magnitude AC supply with which to excite an induction machine. Since the input rectification is readily accomplished using either the fixed diode or the phase-controlled thyristor bridge, the emphasis in adjustable speed AC drive research has been on the inverter. Major technological advances in semiconductor devices such as the FET, GTO and power transistor has enabled the development of inverters capable of controlling AC induction machines with the efficiency and precision previously accorded to DC machines.

The hysteresis current control generates an asymmetrical pulse pattern. The hysteresis band can be fixed or variable over a fundamental period.

\subsubsection{Fixed Band Control}

In this scheme the hysteresis bands are fixed over the fundamental period.

The algorithm for this scheme is:

$$
\mathrm{i}_{\mathrm{ref}}=\mathrm{i}_{\max } \operatorname{sinwt} .
$$

upper band $\mathrm{i}_{\mathrm{u}}=\mathrm{i}_{\text {ref }}+\mathrm{H} / 2$

lower band $\mathrm{i}_{1}=\mathrm{i}_{\text {ref }}-\mathrm{H} / 2$

where $\mathrm{H}=$ hysteresis band limits

\subsubsection{Variable Or Sinusoidal Band Control}

In this scheme the hysteresis band varies sinusoidally over a fundamental period. The upper and lower bands are given as:

$$
\mathrm{i}_{\text {ref }}=\mathrm{i}_{\max } \sin \omega \mathrm{t} \text {. }
$$

$$
\text { upper band } \mathrm{i}_{\mathrm{u}}=\left(\mathrm{i}_{\max }+\mathrm{H} / 2\right) \sin \omega \mathrm{t}
$$

lower band $\mathrm{i}_{1}=\left(\mathrm{i}_{\max }-\mathrm{H} / 2\right) \sin \omega \mathrm{t}$

The hysteresis current controlled converter is as shown below (Fig 1.5):

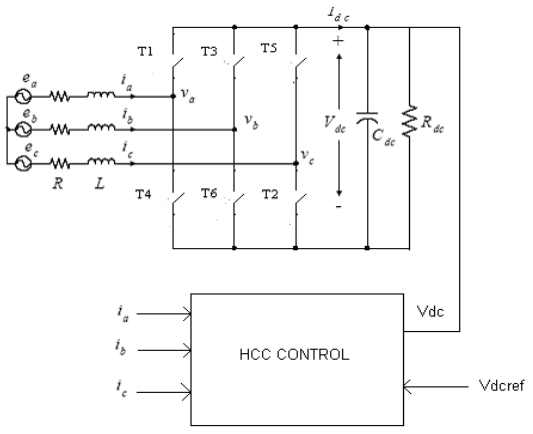

Fig 1.5 Hysteresis Current Controlled Converter

Fig 1.6 explains the operation principle of hysteresis-band PWM for one leg of the three phase converter.

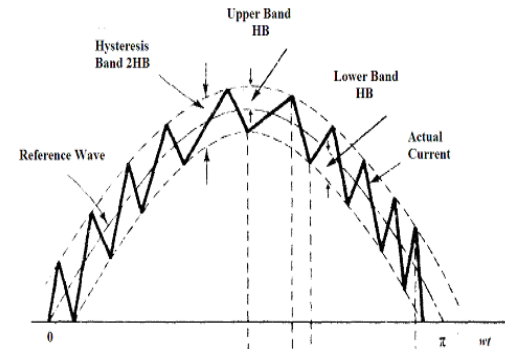

Fig 1.6 Principle of Operation of HCC Controlled Converter 
The control circuit generates the sine reference current wave of desired magnitude and frequency, and it is compared with the actual phase current wave. As the current exceeds a prescribed hysteresis band, the upper switch of the leg is turned of and lower switch is turned on. As the current crosses the lower band limit, the lower switch is turned off and the upper switch is turned on. The actual current wave is thus forced to track the sine reference wave within the hysteresis band by back-and-forth (or bang-bang) switching of the upper and lower switches. The peak-to-peak current ripple and switching frequency are related to the width of the hysteresis band. A smaller band will increase the switching frequency and lower the ripple. So, an optimum band that maintains a balance between the harmonic ripple and switching loss should be chosen.

The control block diagram for implementation of hysteresis band PWM is shown in the figure 1.7. The error in the current control loop is impressed at the input of a comparator with a hysteresis band as shown. The bandwidth of hysteresis band is given as

$$
\mathrm{HB}=\mathrm{V} * \mathrm{R} 2 /(\mathrm{R} 1+\mathrm{R} 2)
$$

Where $\mathrm{V}=$ Comparator supply voltage.

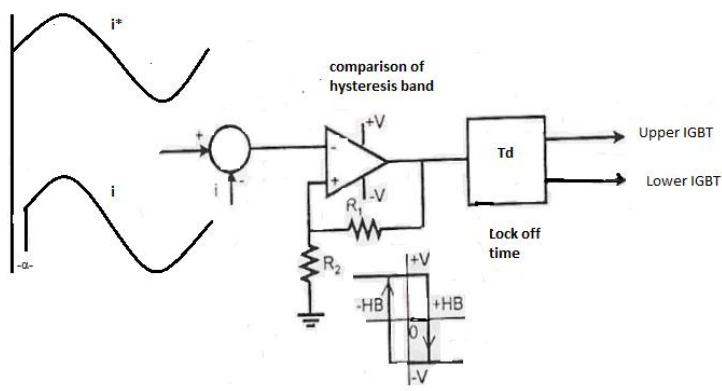

Fig 1.7 Control Block Diagram for Hysteresis Band PWM

The conditions for switching devices are:

Upper switch on: $\left(i^{*}-\mathrm{i}\right)>\mathrm{HB}$

Lower switch on: $\left(i^{*}-\mathrm{i}\right)<\mathrm{HB}$

For the three phase converter, a similar control circuit is used in all the phases.

The advantages of the hysteresis current control scheme can be enlisted as below:

The scheme generates nearly sinusoidal current waveform with unity power factor.

- Implementation is simple.

- Fast transient response.

- Direct limiting of device peak current.

- Practical insensitivity of Dc link voltage ripple that permits a lower filter capacitor.

However this scheme suffers from some disadvantages. The fundamental current suffers a phase lag that increases at higher frequency. The major problem of HCC is that its average frequency Fs varies with the DC load current. At heavy loads, frequency increases substantially. The switching pattern is uneven and random and the instantaneous switching frequency is higher than the average value as shown in the figure 1.8 below causing excessive stress on switching devices.

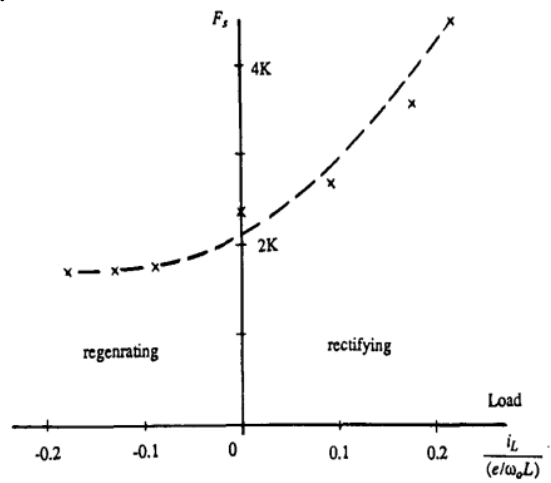

Fig 1.8 Variation of Load with Switching Frequency under HCC 


\section{Indirect Current Control}

Many PWM control schemes for voltage source converters usually employ two or three current sensors to implement the instantaneous current control and to limit the line currents for the protection of the switching devices. But these current sensors bring some additional hardware such as A/D converters in case of digital implementation in its train and cause the system complexity, cost-up and reduction of system reliability. In the indirect control as the name implies, the function of the inner hysteresis current control feedback loop is mimicked and implemented by hardware representing transfer function blocks. The ac currents are indirectly controlled by standard sinusoidal PWM, which essentially modulates the fundamental harmonic component of voltage. In eliminating the inner hysteresis current feedback loop, one dispenses with the need for at least two high-quality broad band-width current measuring transducers. This method falls back on the well-known sinusoidal PWM control in which the switching instants are determined by the intersections of the triangular wave carrier and the modulating sine wave.

\subsection{Principle Of Indirect Current Control}

The objective is to be able to operate the rectifier so that the fundamental harmonic component of the phase current, which is represented by the phasor I in Fig, makes a constant power angle $\phi$. As the rectifier becomes more heavily loaded, it is the current magnitude I that increases. For inverter operation I take a negative value $\left(180^{\circ}\right.$ phase reversal). Considering the fundamental harmonic of the supply frequency only, if the phase circuit impedance is

$$
\mathrm{Z}=\mathrm{R}+\mathrm{j} \omega \mathrm{L}=\mathrm{R}+\mathrm{Jx}
$$

One can indirectly control the current by the fundamental component of the voltage $\mathrm{V}_{\mathrm{ph}}$ at the terminals of the rectifier. Based on Kirchhoff s Voltage Law, the required voltage $V_{\mathrm{ph}}$ is obtained from the equation $\mathrm{V}_{\mathrm{ph}}=\mathrm{V}-\mathrm{IZ}$. (2.13)

The above equation is represented in the phasor diagram of Fig.2.13 In the time-domain, one sees that if $\mathrm{Va}(\mathrm{t})=\sqrt{ } 2 \mathrm{~V}$ sinwt.

Then the requisite control voltage has to be

$$
\mathrm{V}_{\text {pha }}(\mathrm{t})=\sqrt{2} \mathrm{~V}_{\mathrm{ph}}[\cos \xi \sin w \mathrm{t}-\sin \xi \cos w \mathrm{t}]
$$

where the in-phase component is

$$
\mathrm{V}_{\mathrm{ph}} \cos \xi=\mathrm{V}+(\mathrm{X} \sin \varphi-\mathrm{R} \mathrm{c} \varphi) \text {. I }
$$

and the in-quadrature component is

$$
\mathrm{V}_{\mathrm{ph}} \sin \xi=(\mathrm{X} \cos \varphi+\mathrm{R} \sin \varphi) . \mathrm{I}
$$

From (1.9) one sees that since V, R, and X can be measured beforehand from the ac circuit, one can operate at any power angle $\varphi$ for any demand of the current magnitude I provided the in-phase and the quadrature components of $\mathrm{V}_{\mathrm{ph}}$ are made to satisfy (1.9).

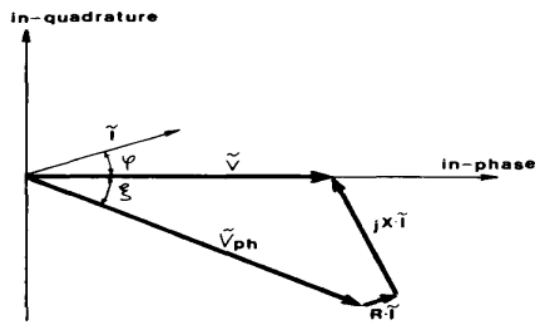

Fig 1.9 Voltage phasor diagram of ac circuit

\subsection{Sinusoidal Pwm Control}

Fig. 2.10 (a) and (b) illustrates the waveforms of $\mathrm{Va}(\mathrm{t})$ and $\mathrm{V}_{\mathrm{ph}}(\mathrm{t})$ The voltage $\mathrm{V}_{\mathrm{ph}}(\mathrm{t})$ is the fundamental component of the voltage at the rectifier terminals, the rectifier being under sinusoidal PWM control. If one imagines the capacitor $\mathrm{C}$ to have a centre-tap, then the waveform of the voltage between the A-phase rectifier terminal and the centre-tap consists of the square wave shown in Fig. 2.10 (c). This modulating waveform switches from $+0.5 \mathrm{Vc}$ to $-0.5 \mathrm{Vc}$, and it are desired that the switching pattern is such that it yields as fundamental component the waveform of $\mathrm{V}_{\mathrm{ph}}(\mathrm{t})$. Fig. 2.10 (d) illustrates how the switching pattern is generated in the conventional sinusoidal PWM strategy. The switching instants are based on the intersections of the triangular waveform $\mathrm{Vt}$ and the modulating sinusoidal waveform $\mathrm{Vm}(\mathrm{t})$. 


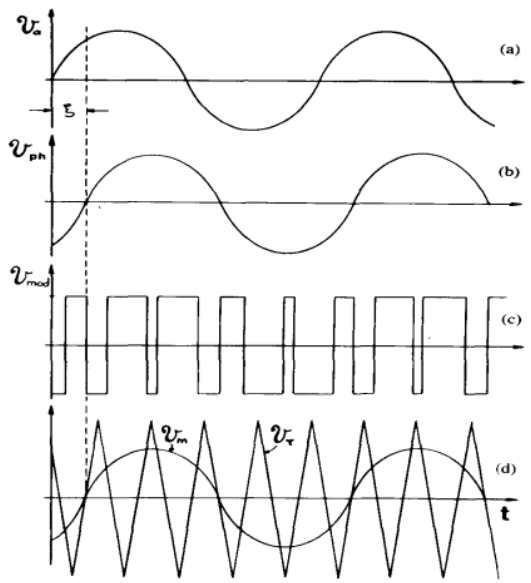

Fig 2.10 (a) A-Phase Supply Voltage (b) Fundamental Component of A-Phase Voltage at Rectifier Terminal (c) Switched Voltage (d) Carrier and Modulating Waveform

\subsection{Modulating Signal $\mathbf{V}_{\mathrm{m}}$}

The generation of the modulating signal of the A-phase is illustrated in the block diagram of Fig.2.11 The input comes from the current magnitude demand I, which is based on the voltage error of the dc link voltage $\mathrm{Vc}$, with respect to the voltage reference Vref. This signal is combined with proportional amplifiers of gains $\mathrm{K}_{1}, \mathrm{~K}_{2}$, and $\mathrm{K}_{3}$, multipliers, and the generators of the in-phase and the in-quadrature waveforms. The inphase waveform generator is taken from the voltage transformer across the line-to-neutral of the A-phase. After filtering its output is

$$
\mathrm{Vx}=\sqrt{2} \mathrm{Vs} \sin \mathrm{wt} \text {. }
$$

The in-quadrature waveform generator is obtained from subtracting the B-phase from the C-phase voltage, and multiplied by $1 / \sqrt{ } 3$ factor so that its output is

$$
\mathrm{Vy}=\sqrt{2} \mathrm{Vs} \cos w \mathrm{t}
$$

For the $\mathrm{Vm}(\mathrm{t})$ prescribed by the functional blocks of Fig. 2.15, the output voltage at the rectifier terminal is $\mathrm{V}_{\text {mod }}(\mathrm{t})=\mathrm{Vs} . \mathrm{Vc}\left[\left(\mathrm{K}_{1}+\mathrm{K}_{2} \mathrm{I}\right) \sin \mathrm{wt}-\mathrm{K}_{3} \mathrm{I} \cos \mathrm{wt}\right] / \sqrt{ } 2 . \mathrm{V}_{\text {tpeak }}+$ Bessel function harmonic terms .(2.20)

The objective is to make the fundamental component in (2.20) identical to (2.15)-(2.17). This is done by choosing the values of the constants $\mathrm{K}_{1}, \mathrm{~K}_{2}$, and $\mathrm{K}_{3}$.

\section{Choosing Constants $K_{1}, K_{2}, K_{3}$ :}

By comparing (2.20) with (2.15)-(2.17), the amplifier gains $\mathrm{K}_{1}, \mathrm{~K}_{2}, \mathrm{~K}_{3}$ are determined as,

$$
\mathrm{K}_{1}=2 \mathrm{~K}_{4} \mathrm{Va} / \mathrm{Vs}
$$

Where $\mathrm{K}_{4}=\mathrm{V}_{\text {tpeak }} / \mathrm{Vc}$

$\mathrm{K}_{2}=2 \mathrm{~K}_{4}(\mathrm{X} \sin \varphi-\mathrm{R} \cos \varphi) / \mathrm{Vs}$

$\mathrm{K}_{3}=2 \mathrm{~K}_{4}(\mathrm{X} \cos \varphi+\mathrm{R} \sin \varphi) / \mathrm{Vs}$

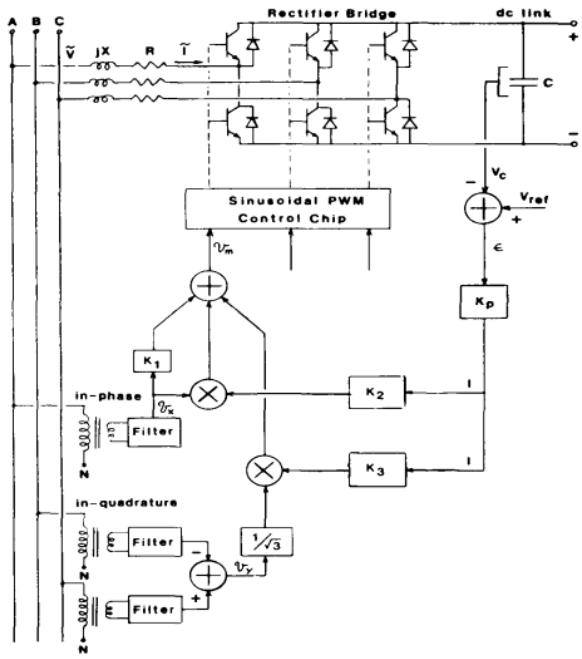

Fig 2.11 Block diagram implementing indirect current control 


\subsection{Four wire PWM rectifiers:}

In the last twenty years the voltage quality concept has become essential both for industrial applications and for daily life. Nowadays, electrical systems have become less and less tolerant as regards to power supply disturbances as harmonics, outages, fluctuation and transients. Moreover, solving the VAR compensation problem is essential in transmission and distribution systems design. The impact of non-linear loads on line harmonic voltages and neutral wire sizing is serious for distribution LV networks. A three-wire AC-boost rectifier has been utilized but its drawback is that the converter line currents cannot be regulated independently the one from the other because their sum must be zero. As a consequence:

* Any voltage disturbance, that is present on all the three supply lines with the same phase (i.e. a third harmonic voltage), cannot be eliminated by the converter.

* HCR control loop ensures that only two of three boost AC currents are within the hysteresis band.

* Voltages on phase to neutral loads cannot be regulated.

* Harmonic and inter-harmonic effects due to single-phase non-linear loads cannot be compensated.

The advantage of using a four wire rectifier is that the sum of line AC-currents is free, so they can be controlled independently the one from the other. As a consequence all kind of PCC (Point of Common Coupling) voltage disturbance can be compensated and harmonic and inter

harmonic effect can be neutralized. However the price to pay using the rectifier as a multi functional converter is an over sizing of the device. One of the main applications of the four-wire rectifier is in the use of transformer less AC-DC-AC converters for uninterruptible power supplies (UPS).

This allows the supply neutral and load neutral of the AC-DC-AC converter to be connected together without the requirement of a transformer where galvanic isolation is not required, without any supply neutral current flowing regardless of the load.

The four-wire power factor corrected boost rectifier (PFCR) is shown in Fig. 2.12. This is similar to the three wire PFCR, but provides a neutral connection from the star point of the supply to the centre point of the DC bus using a centre-tapped capacitor. The topology is similar to a four-wire inverter using centre-tapped capacitors for the load neutral connection. Connecting the DC centre-point to the supply neutral can allow harmonic currents to flow in the supply neutral mainly third harmonic owing to the diodes in the bridge. This can be overcome for the four-wire PFCR if

$$
\mathrm{V}_{\mathrm{dc}}>\sqrt{8} \sqrt{ }\left(\mathrm{V}_{\mathrm{ph}}{ }^{2}+\mathrm{I}_{\mathrm{ph}}{ }^{2} \mathrm{~L}_{\text {boost }}{ }^{2} \omega^{2}\right)
$$

To prevent any low-order harmonic currents flowing in the neutral it is now up to the switch controllers to shape the line currents accordingly. If the three sinusoidal line currents are controlled to keep the amplitudes equal and each with a phase of $120^{\circ}$ apart, the neutral current will always be zero.

$$
\begin{aligned}
I_{n n} & =i_{a}+i_{b}+i_{c} \\
& =I(t)\left[\sin (\omega t)+\sin \left(\omega t-120^{\circ}\right)+\sin \left(\omega t-240^{0}\right)\right. \\
& =0
\end{aligned}
$$

The only neutral current flowing will be a switching frequency ripple current from the summation of the three phases set by the size of the boost inductance in the lines.

This system requires current controllers with a 'good' steady-state and dynamic response to maintain three equally balanced sinusoidal currents during both steady-state and dynamic operation.

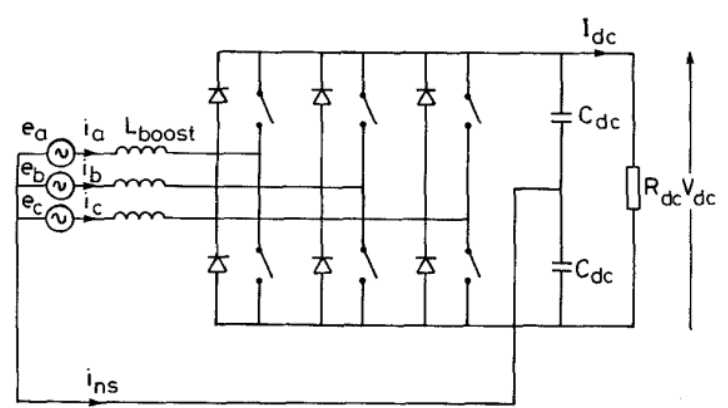

Fig 2.12 Three Phase Four Wire Rectifier

\subsection{Pfcr Control In Stationary Reference Frame}

+ A current-mode control scheme is required for the line currents. There are different forms of currentmode control including peak current-mode control, hysteresis control and average current-mode control. Average current-mode control has significant advantages over hysteresis and peak current-control including constant switching frequency, improved noise immunity and true average current-mode control afforded by sensing and controlling the average inductor current; thus average current-mode control of the line boost inductor current is used here. 


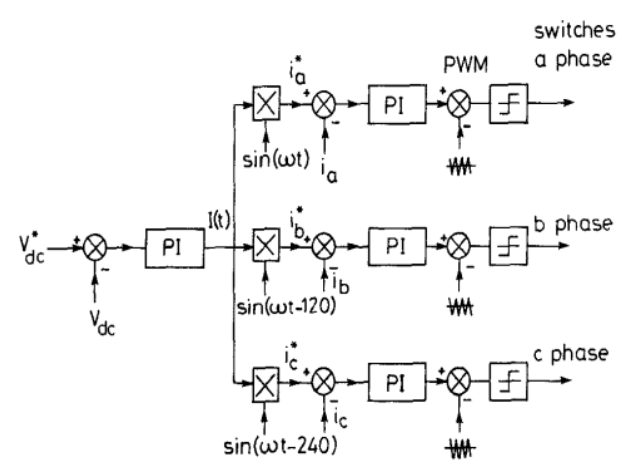

Fig 2.13 Control Circuit of the Four Wire PFCR

The neutral connection in the four-wire PFCR decouples the three phases and allows individual control of each phase. Fig. 2.13 shows the average current mode control system. The inductor current is measured and compared to a reference. The current error is passed through a proportional and integral (PI) controller providing high gain at low frequencies, but having a filtering effect on the high-frequency ripple current. This signal is compared to a triangular carrier wave to generate the required pulse width modulated (PWM) signal to control the switches. The average current-mode controllers form the inner current loops. The DC bus voltage is controlled by measuring the DC bus voltage and comparing it to a reference. This error signal is passed through a PI controller which then forms the current amplitude reference required for all three inner current loops. The current amplitude reference is multiplied by three sinusoidal templates each with a phase $120^{\circ}$ apart to form the true current references. As a unity power factor system is required each sinusoidal reference is in phase with the respective supply phase voltage. The constants of the PI controllers are set to produce a stable system with good steady-state and dynamic response.

\section{Boost Inductance}

The switching action of the PWM rectifier gives a ripple current in the boost inductors. For an average current mode control scheme the ripple current varies over the cycle of the mains, the worse case being when the supply voltage $\mathrm{e}=0$. By approximating the boost inductor current ripple to a triangular wave it can be shown that the worse case ripple is

$\Delta i=\frac{\mathrm{Vdc}}{4 f \mathrm{sL} b o o s t}(p k-p k)$

The ripple current is set by the value of the boost inductance and the switching frequency, but independent of load. The required boost inductance is obtained from eqn1.

\section{De Bus Capacitance}

The DC bus is inherently free from low-order harmonics during steady-state resistive loading apart from the high-frequency ripple voltage. The ripple voltage requires only a relatively small amount of DC capacitance for smoothing. A larger DC capacitance is used though to hold up the DC bus during transient loading and to absorb cyclic power ripple from, say, an inverter load.

The control schemes for three phase single switch rectifier, three phase multi switch rectifier, three phase four wire rectifier have been discussed. The basic principle, control circuit and implementation of the scheme for a three phase AC-to-DC converter are described. The advantages and disadvantages of each strategy are stated and the area of application is given.

\section{Space Vector Modulation}

Space Vector modulation (SVM) technique was originally developed as a vector approach to pulsewidth modulation (PWM) for three-phase inverters. It is a more sophisticated technique for generating sine wave that provides a higher voltage to the motor with lower total harmonic distortion. It confines space vectors to be applied according to the region where the output voltage vector is located. A different approach to PWM modulation is based on the space vector representation of voltage in the $\alpha-\beta$ plane. The $\alpha-\beta$ components are found by transformations. The determination of switching instant may be achieved using space vector modulation technique based on the representation of switching vectors in $\alpha-\beta$ plane.

The Space vector modulation technique is an advanced, computation intensive PWM technique and is possibly the best among all the PWM techniques for drives applications. Because of its superior performance characteristics, it is been finding wide spread application in recent years. 


\subsection{Features Of Space Vector Pwm}

The main aim of any modulation technique is to obtain variable output having a maximum fundamental component with minimum harmonics. During the past years many PWM techniques have been developed for letting the inverters to posses various desired output characteristics to achieve the following aim:

* wide linear modulation range

* Less switching loss.

* Lower total harmonic distortion.

The space vector modulation (SVM) technique is more popular than conventional technique because of the following excellent features:

* It achieves the wide linear modulation range associated with PWM third-harmonic injection automatically.

* It has lower base band harmonics than regular PWM or other sine based modulation methods, or otherwise optimizes harmonics.

* $15 \%$ more output voltage then conventional modulation, i.e. better DC-link utilization.

* More efficient use of DC supply voltage.

* SVM increases the output capability of SPWM without distorting line-line output voltage waveform.

- Advanced and computation intensive PWM technique.

* Higher efficiency.

* Prevent un-necessary switching hence less commutation losses.

* A different approach to PWM modulation based on space vector representation of the voltages in the $\alpha-\beta$ plane.

\subsection{Space Vector Concept}

The concept of space vector is derived from the rotating field of $\mathrm{AC}$ machine which is used for modulating the inverter output voltage. In this modulation technique the three phase quantities can be transformed to their equivalent 2-phase quantity either in synchronously rotating frame (or) stationary frame. From this 2-phase component the reference vector magnitude can be found and used for modulating the inverter output. The process of obtaining the rotating space vector is explained as below, considering the stationary reference frame.

Let the three phase sinusoidal voltage component be,

$\mathrm{V}_{\mathrm{a}}=\mathrm{V}_{\mathrm{m}} \sin \omega \mathrm{t}$

$\mathrm{V}_{\mathrm{b}}=\mathrm{V}_{\mathrm{m}} \sin (\omega \mathrm{t}-2 \pi / 3)$

$\mathrm{V}_{\mathrm{c}}=\mathrm{V}_{\mathrm{m}} \sin (\omega \mathrm{t}-4 \pi / 3)$

When this 3-phase voltage is applied to the AC machine it produces a rotating flux in the air gap of the AC machine. This rotating flux component can be represented as single rotating voltage vector. The magnitude and angle of the rotating vector can be found by mean of Clark's Transformation as explained below in the stationary reference frame. The representation of rotating vector in complex plane is shown in Figure 3.1.

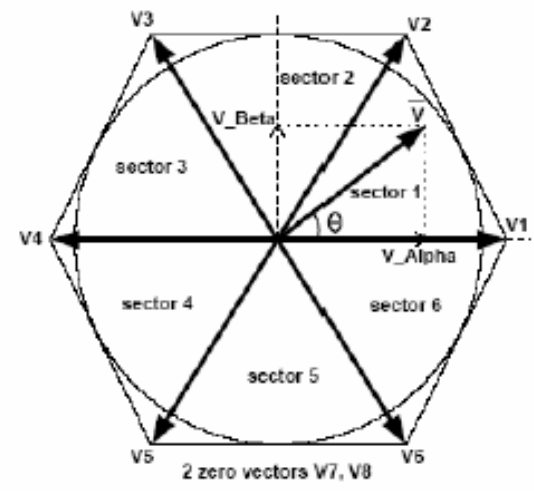

Fig 3.1 Representation of Rotating Vector in Complex Plane 


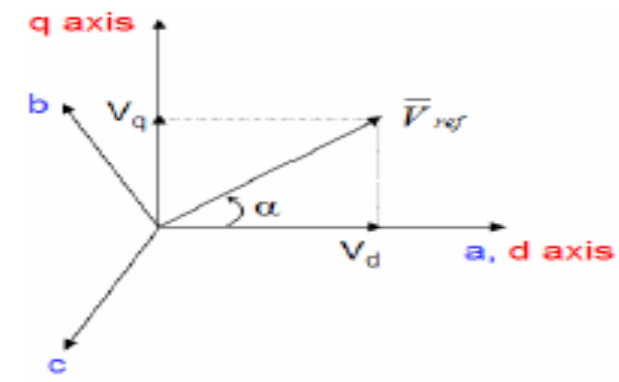

Fig 3.2 Voltage Space Vector and its components in d-q

\subsection{Principle Of Space Vector Pwm}

* Treats the sinusoidal voltage as a constant amplitude vector rotating at constant frequency.

- This PWM technique approximates the reference voltage $\mathrm{V}_{\text {ref }}$ by a combination of the eight switching patterns (V0 to V7).

- Coordinate Transformation (abc reference frame to the stationary d-q frame): A three-phase voltage vector is transformed into a vector in the stationary $\mathrm{d}$-q coordinate frame which represents the spatial vector sum of the three-phase voltage.

\section{Key issues and challenges in harmonics estimation}

The emerging power system will consist of renewable energy sources, smart grid solutions comprising of FACTS devices and non-linear loads like power electronics based equipments, electric vehicles etc. Harmonic estimation is very important to know the harmonic components and their magnitudes for designing the harmonic mitigation devices and other controllers. The harmonics estimation should be fast enough for real time application, highly accurate for better reliability, simple for easy practical implementation and economical too. Power system is highly dynamic in nature, hence, network topology and parameters keep on changing rapidly. The harmonics estimation therefore should be adaptive in nature. It should also be robust against noise and transients present quite often in the measured data.

\section{Comparative Analysis Of Control Strategies}

The comparative analysis of control strategies is given. Some performance measures are specified and calculated for all the rectifiers and finally the results are tabulated.

Normally the input voltage to an AC-to-DC converter is sinusoidal but the input current is nonsinusoidal i.e. harmonic currents are present in the ac lines. This has two main adverse effects. These harmonic currents conduct through the ac lines and interfere with other equipment connected to the same lines. Furthermore they cause electromagnetic interference to nearby telephone and communication lines. However the input current can be made nearly sinusoidal with the above control strategies and unity power factor operation can also be achieved. Even though the input current is controlled there is a ripple in the output voltage which in turn generates ripple in the output current. This ripple current has several adverse effects.

\section{External Performance Measures}

Input Displacement factor (IDF): This is defined as the cosine of the input displacement angle $\varphi$ which is the angular displacement between the fundamental component of the ac supply current and the associated line to neutral voltage. It is also known as the fundamental power factor (FPF).

Input Power Factor (IPF): This is defined as the ratio of the total mean input power to the total rms apparent power input to the converter. Since only the fundamental component contributes to the mean input power, the PF may be defined as

$\mathrm{PF}=\mathrm{V}[\mathrm{I}] \cos \varphi / \mathrm{V}_{\mathrm{rms}} \mathrm{I}_{\mathrm{rms}}=\left(\mathrm{I} 1 / \mathrm{I}_{\mathrm{rms}}\right) \cos \varphi$

Where $\mathrm{V} 1=\mathrm{V}_{\mathrm{rms}}=$ Phase Voltage

I1 $=$ Fundamental component of the supply current

$\Phi=$ Input displacement angle

$\mathrm{I}_{\mathrm{rms}}=$ Supply rms current

Input current distortion factor: It is defined as the ratio of the rms amplitude of the fundamental component to the rms amplitude. It is a measure of the distortion present in the supply current.

Input Harmonic factor: It is the ratio of the total harmonic content to the fundamental component $\mathrm{IH}=(\mathrm{Irms} 2-\mathrm{I} 12) 1 / 2 / \mathrm{I} 1$ 
Voltage Ripple factor: It is defined as the ratio of the net harmonic content of the output voltage to the average output voltage.

$$
\mathrm{KV}=(\mathrm{V} 0 \mathrm{rms} 2-\mathrm{V} 0 \mathrm{av} 2) 1 / 2 / \mathrm{V} 0 \mathrm{av}
$$

Crossover time: This is defined as the time taken by the input current to reach a steady state value when the operating mode of the AC-to-DC converter changes from generating to regenerative.

Response time: It is defined as the time taken by the output DC voltage of the converter to reach a steady state value.

\section{Outputs And Comparison}

For a comparative analysis of the control strategies studied, all the above parameters have been calculated for each strategy under different load conditions and switching conditions. These are enlisted in the tables below.

These control schemes are compared on the basis of some plots which give the variation of output power with various parameters like THD of input current, magnitude of input current, input power factor, input harmonic factor. These graphs are shown below.

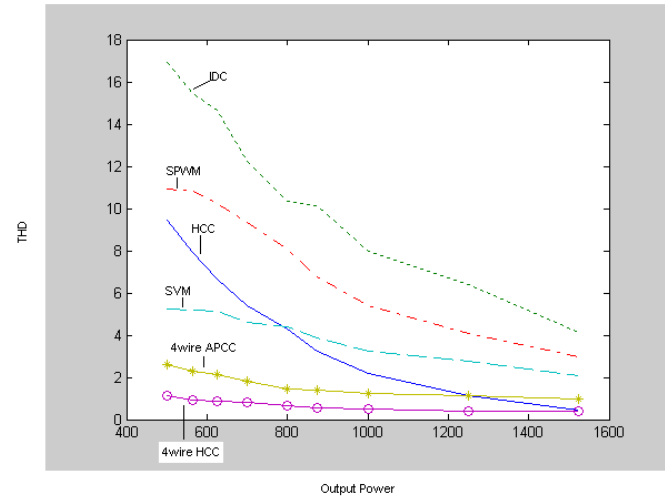

Fig 5.1 Output power Vs THD

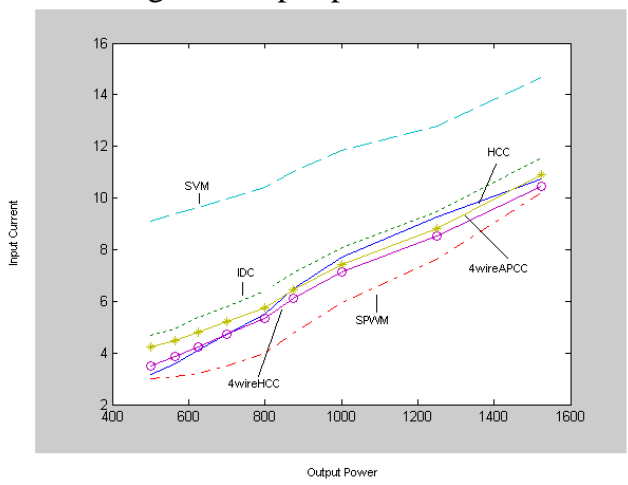

Fig 5.2 Output power Vs Input current

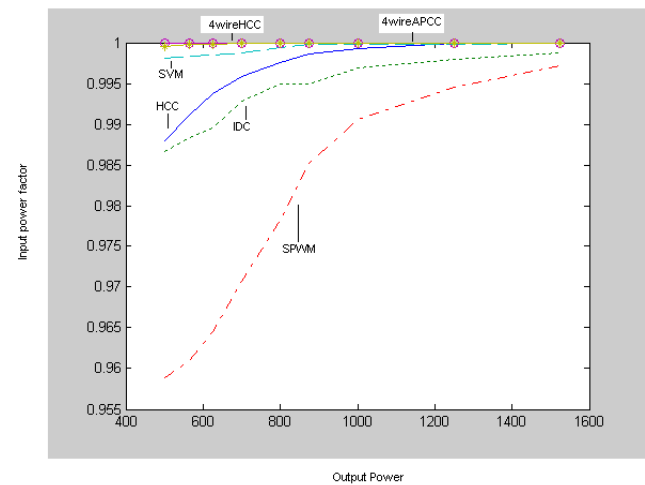

Fig 5.3 Output Power Vs Input power factor 


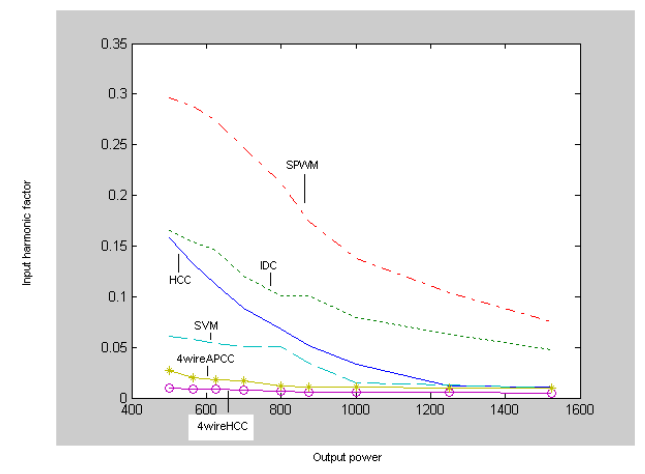

Fig 5.4 Output power Vs Input harmonic factor

From graph 5.1, it can be observed that the THD is the highest for indirect current control scheme whereas it is the lowest from 4 wire rectifier under HCC. The magnitude of input current is the highest for SVM (Graph 5.2)

All the control schemes have been compared on the basis of a number of parameters. At the end graphs are plotted and compared to decide the best scheme. Each scheme has its own advantages and disadvantages. The selection of the control strategy to be used depends upon the application and requirements of the system. In HCC scheme the switching frequency does not remain constant which increases the switching losses of the converter. The space vector modulation technique is definitely an improvement over the sinusoidal pulse width modulation technique as the THD of the source current is reduced and the magnitude of input current is very high in SVM as compared to SPWM. Though the indirect current control scheme has a higher THD in the source current, the output DC voltage is high. The boost rectifier with single switch has the highest magnitudes of both the input current and the output voltage when compared to all other schemes. However this converter suffers from the disadvantage of higher THD in the input current and more ripples in the output DC voltage. The four wire rectifiers have proven to be better than the three wire rectifiers with respect to the THD of the source current, THD of output voltage, response time and crossover time. However the ripple factor of the output voltage is high in these rectifiers as compared to their three wire counterparts.

\section{Conclusion}

Many new PWM control schemes are being developed which improve the performance of the converter. The indirect current control without the need of current sensors is an improvement over the hysteresis current control scheme as the switching frequency remains constant and all the advantages of HCC are retained. Artificial Intelligence techniques are being developed for the implementation of control techniques in power electronics. Some of these are fuzzy logic control, artificial neural networks. Space vector modulation implementation is much easier using neural network training method as compared to the one that employs the dq transformation.

\section{References-}

[1] Martin Jones *, I. Nyoman Wahyu Satiawan,"A simple multi-level space vector modulation algorithm for five-phase open-end winding drives." ELSEVIER 5 October 2011; 90 (2013) 74-85.

[2] Abderrahim El Fadili n, Fouad Giri "Adaptive control strategy with flux reference optimization for sensorless induction motors." ELSEVIER 26 (2014) 91-106.

[3] Péter Stumpf a,*, Rafael K. Járdán b, István Nagyb, "Analysis of the impact of space vector modulation techniques on the operation of ultrahigh speed induction machines".ELSEVIER 90 (2013) 132-144.

[4] Tarak Ghennama,* , El-Madjid Berkoukb,1 "Back-

[5] converter controlled by a novel space-vector hysteresis current control for wind conversion systems", ELSEVIER 80 (2010) 444455.

[6] Aunnon Buasrea,b,* and Wanchai Subsinghaa*, "Double-Sided Linear Induction Motor Control usingSpace Vector Pulse Width Modulation Technique”, ELSEVIER 34 ( 2013 ) 181 - 188.

[7] Mekri Fatihaa,*, Machmoum Mohamedb, Ait-Ahmed Nadiab, "New hysteresis control band of an unified power quality conditioner", ELSEVIER 81 (2011) 1743-1753..

[8] Lutfu Saribulut*, Ahmet Teke, Mehmet Tumay, "Vector-based reference location estimating for space vector modulation technique", ELSEVIER 86 (2012) 51-60, 30 November 2011

[9] Singh.B, Chandra.A, Al-Haddad.K, "A review of active filters for power quality improvement," IEEE Trans. Industrial Electronics, Vol. 46, pp. 960-971, Oct. 1999

[10] António P. Martins "The Use of an Active Power Filter for Harmonic Elimination and Power Quality Improvement in a Nonlinear Loaded Electrical Installation”, Institute of Systems and Robotics - Porto ,Faculty of Engineering - University of Porto ,Rua Dr Roberto Frias, s/n, 4200-465, Porto, Portugal

[11] RASHID_Power_Electronics_Handbook.

[12] Akagi.H, "Control strategy and site selection of a shunt active filter for damping of harmonic propagation in power distribution systems," IEEE, Trans. Power Delivery, Vol.12, pp.354-363, Jan. 1997. 
[13] Singh.B, Chandra.A, Al-Haddad.K, "A new control approach to three-phase active filter for harmonics and reactive power compensation," IEEE, Trans. Power Systems, Vol.13, pp. 133 - 138, Feb.1998.

[14] Hirofumi Akagi, Akira Nabae, Satoshi Atoh, "Control Strategy of Active Power filters using multiple voltage source PWM converters", IEEE, transactions on Industry Applications, Vol 1A-22, No 3, May/June 1986.

[15] Singh, B.N.; Chandra, A.; Al-Haddad, "Performance Comparison of Two Current Control Techniques Applied to an Active Filter", IEEE, Volume 1, 14-16 Oct. 1998,pp.133 - 138 vol.1.

[16] Chandra.A, Singh.B, SinghB.N, Al-Haddad.K, "An improved control algorithm of shunt active filter for voltage regulation, harmonic elimination, power-factor correction, and balancing of nonlinear loads," IEEE, Trans. Power Electronics, Vol.15, pp. 495-507, May 2000.

[17] Rahman, M.A.Radwan, T.S. Osheiba, "Analysis of current controllers for voltage-source inverter" Volume 44, Issue 4, Aug. 1997 Page(s):477 - 485

[18] Dixon, J.W, Ooi, B.T, "Dynamically stabilized indirect current controlled PWM boost type 3-phase rectifier" 2-7 Oct. 1988 Page(s):700 - 705 vol.1

[19] Singh, B.N. Chandra, A.Al-Haddad, "Indirect-current-controlled STATCOM. II. Multifunctional capabilities "Volume 147,Issue 2, March 2000 Page(s): $113-118$

[20] B. Singh, K. Al-Haddad, and A. Chandra, "Harmonic elimination, reactive power compensation and load balancing in three-phase, four wire electric distribution systems supplying nonlinear loads,’J. Electric Power Syst. Res., vol. 44, pp. 93-100, 1998.

[21] P. T. Cheng, S. Bhattacharya, and D. M. Divan, "Control of square-wave inverters in high-power hybrid active filter systems," IEEE, Trans. Ind. Applicat., vol. 34, pp. 458-472, May/June 1998.

[22] Q. Yao and D. G. Holmes, "A simple novel method for variable hysteresis band current control of a three phase inverter with constant switching frequency," in Conf. Rec. 28th IEEE -IAS Annu. Meeting, 1993, pp. 1122-1129.

[23] B. K. Bose, "An adaptive hysteresis-band current control technique of a voltage-fed PWM-inverter for machine drive system,” IEEE, Trans. Ind. Electron. vol. 37, pp. 402-408, Oct. 1990.

[24] Alexander Varschavsky, Juan Dixon ,Mauricio Rotella, and Luis Morán, Fellow, “Cascaded Nine-Level Inverter for Hybrid-Series Active Power Filter Using Industrial Controller ", Senior Member, IEEE, Transactions On Industrial Electronics, vol. 57, no. 8, august 2010 .

[25] J. Dixon, S. Tepper, L Moran, "Practical evaluation of different modulation techniques for current controlled voltage source inverter".

[26] Yong-Sin Jin*,Hee-Keun Shin* “A Carrier Comparison PWM Method for Reducing Input Current THD of Three-Phase PWM Rectifier" 2012 IEEE 7th International Power Electronics and Motion Control Conference - ECCE Asia June 2-5, 2012

[27] V. B. Sriram, Sabyasachi SenGupta, Member, IEEE, and Amit Patra,Member, IEEE "Indirect Current Control of a SinglePhaseVoltage-Sourced Boost Type Bridge Converter Operated in the Rectifier Mode" IEEE, transactions on power electronics, vol. 18, NO. 5, September 2003

[28] K. Georgakas A. Safacas" Modified sinusoidal pulse-width modulation operation technique of an AC-AC single-phase converter to optimise the power factor" IET Power Electron., 2010, Vol. 3, Iss. 3, pp. 454-464

[29] Bhim Singh, Fellow, IEEE, Sanjeev Singh, Member, IEEE, Ambrish Chandra " Comprehensive Study of Single-Phase AC-DC Power Factor Corrected ConvertersWith High-Frequency Isolation" IEEE November Transactions On Industrial Informatics, VOL. 7, NO. 4, 2011

[30] Hasan K"om"urc"ugil, Member, IEEE, and Osman K"ukrer, Member, IEEE “A Novel Current-Control Method for Three-Phase PWM AC/DC Voltage-Source Converters” IEEE, Transactions On Industrial Electronics, vol. 46, NO. 3, JUNE 1999. 